\title{
Percutaneous transcatheter myectomy of subvalvar pulmonary stenosis in tetralogy of Fallot: a new palliative technique with an atherectomy catheter
}

\author{
S A Qureshi, J M Parsons, M Tynan
}

\begin{abstract}
A male infant with tetralogy of Fallot was given a modified left Blalock-Taussig shunt at 11 days of age because of duct dependence. Twenty months later, because of increasing cyanosis and polycythaemia, he was given palliative treatment with balloon dilatation of the right ventricular outflow tract. Seven months later a right ventricular angiogram showed further progression of the infundibular stenosis with poor anterograde opacification of the pulmonary arteries. He underwent percutaneous transcatheter myectomy of the infundibulum with an atherectomy catheter. One month later he was well and less cyanosed.
\end{abstract}

Pulmonary atresia associated with the tetralogy of Fallot is usually congenital. Occasionally, atresia may develop at the infundibular level after a systemic to pulmonary artery shunt operation. ${ }^{12}$ A valved conduit is sometimes required for complete repair in this situation which may then be associated with an increased morbidity and operative mortality..$^{3}$

Although it is not possible to identify patients with tetralogy of Fallot who may develop pulmonary atresia, any intervention that prevents this complication may, ultimately, reduce the risks associated with complete surgical repair. Brock achieved effective palliation through closed infundibular resection or dilatation. ${ }^{245}$ Similarly, balloon dilatation of the right ventricular outflow tract has recently been shown to be of value in infants and children with tetralogy of Fallot. $^{67}$

We report the successful use of a new technique of transcatheter myectomy of the infundibulum in a child with tetralogy of Fallot.

\section{Case report}

Tetralogy of Fallot was diagnosed in a one day old boy who weighed $2.5 \mathrm{~kg}$. Cross sectional echocardiography showed confluent, but small, pulmonary arteries and severe pulmonary valvar and infundibular stenosis. When he was 11 days old he was given a modified ( $5 \mathrm{~mm}$ polytetrafluoroethylene) left BlalockTaussig shunt because of severe cyanosis and dependence upon prostaglandin $\mathrm{E}_{2}$ to maintain the patency of the ductus arteriosus.

At 14 months of age he was moderately cyanosed with a haemoglobin concentration of $19.3 \mathrm{~g} / \mathrm{l}$. Cardiac catheterisation showed that the pressure in the pulmonary artery (entered retrogradely through the shunt) was $10 / 0$ (mean 8) $\mathrm{mm} \mathrm{Hg}$ and the aortic pressure was $120 / 70$ (mean 90) $\mathrm{mm} \mathrm{Hg}$. The aortic saturation was $81 \%$ in air. A right ventricular angiogram showed a trivial amount of contrast flowing through the infundibulum into the pulmonary trunk. The right ventricular outflow tract was dilated with a $5 \mathrm{~mm}$ balloon catheter and then a $8 \mathrm{~mm}$ balloon catheter. $\mathrm{He}$ was reinvestigated seven months later. Angiography showed severe infundibular stenosis. He underwent further balloon dilatation of the right ventricular outflow tract followed by transcatheter myectomy of the infundibulum with an atherectomy catheter.

\section{Technique}

Cardiac catheterisation was performed under general anaesthesia. The left femoral artery was cannulated with an $18 \mathrm{G}$ Abbocath. Catheters were also introduced percutaneously into the right and left femoral veins. The right ventricular systolic pressure was $110 \mathrm{~mm} \mathrm{Hg}$, the femoral artery pressure $125 / 60$ (mean 80) $\mathrm{mm} \mathrm{Hg}$, and the main pulmonary artery pressure 17/11 (mean 13) $\mathrm{mm} \mathrm{Hg}$. Saturations in the femoral artery were $78 \%$ and in the pulmonary artery $69 \%$. A selective injection of contrast with the catheter in the infundibulum showed severe subvalvar pulmonary stenosis caused by hypertrophy of the infundibulum (fig 1). To allow an 8 French transseptal sheath (Bard International) to be passed into the pulmonary trunk, the outflow tract was dilated with an $8 \mathrm{~mm}$ diameter balloon catheter by the standard technique. The level of the infundibulum was marked with a needle positioned externally on the patient's chest. The 8 French
Guy's Hospital, St Thomas

Accepted for publication

11 April 1990 
Figure 1 Selective angiogram in the infundibulum (anteroposterior projection) taken at start of procedure, showing gross hypertrophy of the infundibulum.
Figure 2 (A)

Atherectomy catheter (on anteroposterior $x$ ray screening) in position during myectomy. The balloon was inflated balloon was inflated
(hollow arrow), the cutting window (small arrows) was in contact with the infundibulum, and the drill, which was being advanced, can be seen (large arrow). (B) Selective angiogram in the infundibulum (anteroposterior projection) after myectomy. The outflow tract was wider and the surface of the infundibulum (arrow) was irregular.

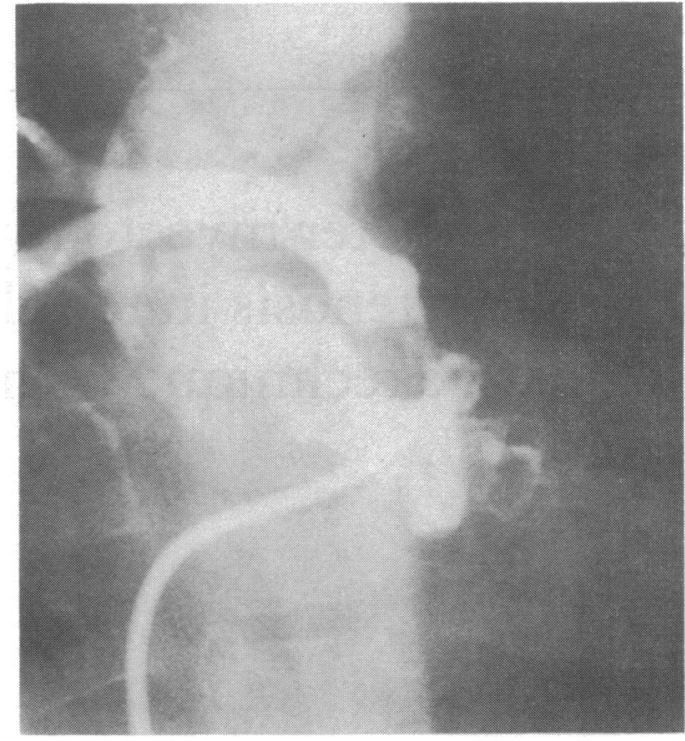

transseptal sheath and its dilator were advanced over an 0.035 inch guide wire and positioned in the proximal pulmonary trunk. The 6 French, Simpson coronary atherectomy catheter (Devices for Vascular Intervention) with a "nose cone" distal to the cutting window was prepared by purging the lumen port and $1.5 \mathrm{~mm}$ diameter balloon. The guide wire and the dilator were removed, leaving the sheath across the pulmonary valve. We introduced an 0.014 inch exchange guide wire through the sheath and advanced the atherectomy catheter over the wire until it was positioned across the infundibulum, using the landmarks from the marker needle. The sheath was then withdrawn and the catheter was rotated until the cutting window pointed postero-medially. The balloon

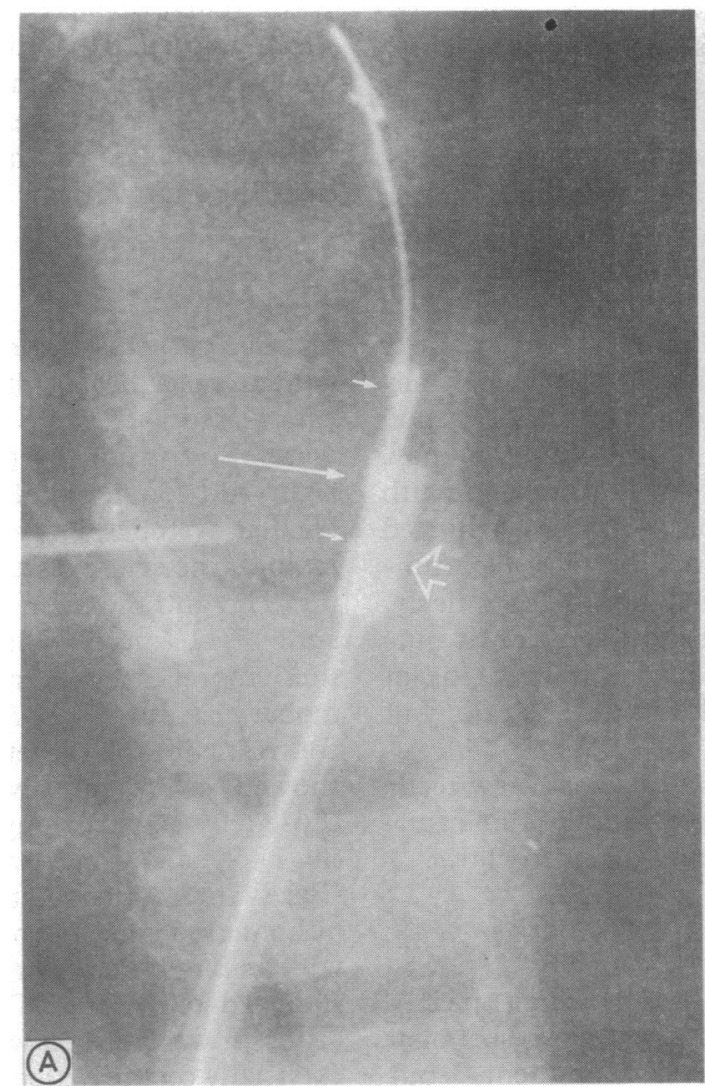

was then fully inflated to a pressure of 4 atmospheres and the drill was activated by the motor drive unit and advanced manually (fig 2A). Nine cuts were made with the cutting window in different orientations. The balloon was deflated and the sheath advanced over the atherectomy catheter which was then removed. A further balloon dilatation with an $8 \mathrm{~mm}$ diameter balloon was then performed. All of the pieces of resected tissue were removed from the "nose cone". Microscopic examination confirmed that they were myocardium and fibrous tissue. A selective angiogram in the infundibulum showed a wider and irregular outflow tract (fig 2B). At the end of the procedure, the pressure was 16/7 (mean 10) $\mathrm{mm} \mathrm{Hg}$ in the pulmonary artery, $125 / 80$ (mean 100 ) $\mathrm{mm} \mathrm{Hg}$ in the descending aorta, and $110 \mathrm{~mm} \mathrm{Hg}$ in the right ventricle during systole. Oxygen saturation was $67 \%$ in the pulmonary artery and $81 \%$ in the descending aorta. There were no complications during or after the procedure. One month later he was well, less cyanosed, and the saturation by pulse oximetry was $85 \%$.

\section{Discussion}

Many centres adopt a staged surgical approach in the treatment of tetralogy of Fallot. ${ }^{389}$ This consists of the creation of a systemic to pulmonary artery shunt followed later by complete repair. This approach has the advantage of allowing continued growth of the pulmonary valve ring and pulmonary arteries, thus reducing the need for a transannular patch and decreasing the operative risk. ${ }^{3}$ Occasionally, however, atresia may be developed at the

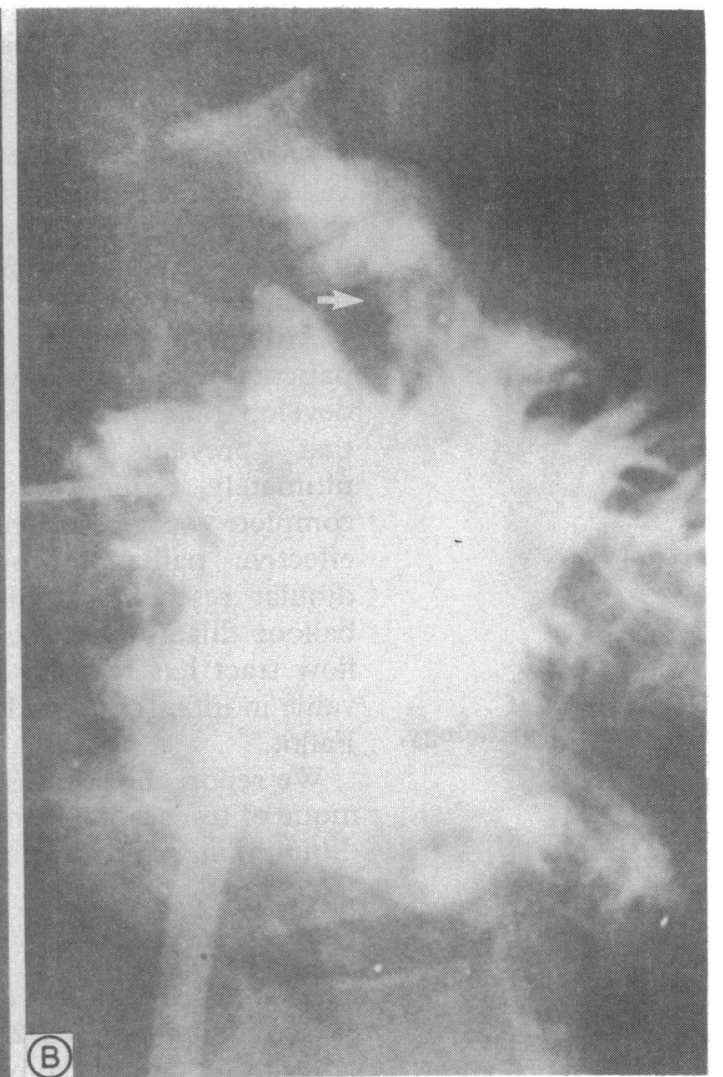


infundibular level after a previous shunt operation. ${ }^{12}$ Such a situation requires an extensive outflow patch or a conduit for complete repair. ${ }^{13}$ Brock first reported the technique of infundibular resection and dilatation in $1948 .^{4}$ He believed, as did Matthews and Belsey, ${ }^{10}$ that increasing anterograde flow across the right ventricular outflow tract not only achieved adequate palliation but was more likely to promote the growth of the pulmonary valve ring, trunk, and arteries. ${ }^{2}$ Recently balloon dilatation of the right ventricular outflow tract has been used as a non-surgical method of increasing anterograde pulmonary blood flow ${ }^{67}$ and has produced adequate palliation. A further report has indicated that an increase in the size of the pulmonary valve ring, trunk, and arteries may also occur after balloon dilatation. ${ }^{11}$

In our patient palliation after balloon dilatation, though initially effective, was limited by further increase in the infundibular obstruction. After another balloon dilatation to facilitate the passage of a large sheath through the infundibulum, we were able to proceed with myocardial resection. Histology confirmed that the resected pieces were myocardium and fibrous tissue.

Atherectomy catheters are currently under evaluation in peripheral vascular and coronary artery disease. ${ }^{12} 13$ We showed the successful application of an atherectomy catheter for the resection of the infundibulum in a child with tetralogy of Fallot.

We suggest that transcatheter resection of the infundibulum may be important in the palliation of the tetralogy of Fallot and possibly other conditions characterised by fibro- muscular stenosis. However, further modifications of the atherectomy catheter are needed for this technique to become widely accepted.

We thank Dr J B Simpson, cardiologist at Sequoia Hospital, Redwood City, California, USA, and Mr B Hinch of Intervention Ltd, UK.

1 Kirklin JW, Barratt-Boyes BG. Cardiac surgery. New York: Wiley Medical, 1986:749-802.

2 Brock RC. Late results of palliative operations for Fallot's tetralogy. J Thorac Cardiovasc Surg 1974;67:511-8.

3 Kirklin JW, Blackstone EH, Kirklin JK, Pacifico AD, Aramendi J, Bargeron LM. Surgical results and protocols in the spectrum of tetralogy of Fallot. Ann Surg 1983;198:251-64.

4 Brock RC. Pulmonary valvulotomy for relief of congenita pulmonary stenosis. Report of 3 cases. $\mathrm{Br}$ Med 1948;i:1121-6.

5 Brock RC, Campbell M. Infundibular resection or dilatation for infundibular stenosis. Br Heart J 1950;12:403-24.

6 Qureshi SA, Kirk CR, Lamb RK, Arnold R, Wilkinson JL. Balloon dilatation of the pulmonary valve in the first year of life in patients with tetralogy of Fallot: a preliminary study. Br Heart J 1988;60:232-5.

7 Qureshi SA, Ladusans EJ, Parsons JM, Baker EJ, Tynan MJ. Efficacy of percutaneous balloon dilatation of the pulmonary outflow tract as palliation of tetralogy of Fallot pulmonary outflow tract as palliation

8 Kirklin JW, Blackstone EH, Pacifico AD, Brown RN, Bargeron LM Jr. Routine primary repair vs two stage repair of tetralogy of Fallot. Circulation 1979;60:373-86.

9 Rittenhouse EA, Mansfield PB, Hall DG, et al. Tetralogy of Fallot: selective staged management. $J$ Thorac Cardiovasc Surg 1985;89:772-9.

10 Matthews HR, Belsey RHR. Indications for the Brock operation in current treatment of tetralogy of Fallot. Thorax 1973;28:1-8.

11 Parsons JM, Ladusans EJ, Qureshi SA. Growth of the pulmonary artery after neonatal balloon dilatation of the right ventricular outflow tract in an infant with the tetralogy of Fallot and atrioventricular septal defect. Br Heart $J$ 1989;62:65-8.

12 Simpson JB, Matthew RS, Robertson GC, et al. Transluminal atherectomy for occlusive peripheral Transluminal atherectomy for occlusive periph
vascular disease. Am J Cardiol 1988;61:96G-101G.

13 Simpson JB, Robertson GC, Selmon MR. Percutaneous coronary atherectomy [Abstract]. Circulation 1988;78 (suppl II):326. 